\title{
HAMLET E AS TECNOLOGIAS DA MOBILIDADE, UBIQQUIDADE E... DESCONECTOPIA
}

\section{POWERS, William. O BlackBerry de Hamlet - Filosofia prática para viver bem na era digital. Trad. Daniel Abrão. São Paulo: Alaúde Editorial, 2012.}

\section{Monike Caroline Zirke Machado* \\ Rafael Cunha**}

Tão instigante quanto pensar em por que um livro não científico integra uma seção de uma revista científica da área da educação é pensar em por que o mesmo livro - que prega uma desconectopia - entra para a lista dos best-seller do New York Times na semana de sua publicação, justamente no seio de uma das sociedades mais conectadas do mundo, em plena era digital. Que filosofia é essa, afinal, que o autor defende e o que Hamlet tem a ver com isso? E por que em países em que os problemas de conexão e acesso às tecnologias já estão praticamente superados há vários anos surgem outras preocupações, como os efeitos do excesso de conexão? Quais relações podemos estabelecer entre os relatos e tópicos levantados no livro e as questões mais amplas que estão balizando as discussões sobre cultura digital e inserção das tecnologias digitais na educação brasileira? É sobre estas e outras questões que William Powers nos convida a refletir em seu original, leve, instigante e ao mesmo tempo alegre O BlackBerry de Hamlet, lançado no Brasil em 2012 pela Alaúde Editorial, com tradução de Daniel Abrão.

Jornalista e ex-redator do jornal Washington Post, William Powers publica, atualmente, textos e artigos sobre mídia e tecnologias em diversos jornais e revistas norte americanos. Sua preocupação central em O BlackBerry de Hamlet são as telas - forma genérica como o autor designa todos os aparelhos digitais utilizados na contemporaneidade, da TV aos dispositivos móveis, como telefones celulares e tablets -, mais precisamente em

\footnotetext{
*Mestranda em Educação pela Universidade do Estado de Santa Catarina. E-mail: monikezinha_m@hotmail.com

** Doutorando em Educação pela Universidade Federal de Santa Catarina. Email: rafael10@hotmail.com
} 
como viver num contexto ubíquo de hiperconectividade sem que o uso das tecnologias afetem negativamente as relações interpessoais e a capacidade de reflexão crítica (a "profundidade”). Para tanto, o autor utiliza suas próprias experiências pessoais e as observações que tem feito em diferentes segmentos da sociedade para superar o que chama de "enigma da conectividade”. Pautando-se em filósofos e pensadores de diferentes épocas, Powers cria um relato despojado e descontraído em que chama atenção para a autonomia e a autossuficiência do homem em relação às tecnologias digitais, sem as quais o uso caótico, perpétuo e em excesso das telas não faz sentido. $\mathrm{O}$ argumento central, portanto, é o equilíbrio entre a vida on-line, conectada; e a vida off-line, desconectada.

O livro está dividido em três partes, segmentadas ao todo em 13 capítulos. A primeira parte, “Qual é a graça? - O enigma da vida em rede”, é composta por quatro capítulos. Neles, Powers tem a intenção de, com relatos de suas próprias experiências, fazer com que seus leitores compreendam que estar conectado às telas, apesar de irresistível, exige pausas, para que seja possível alcançar produtividade e profundidade em nossas ações.

O autor, ainda que demonstre ser um grande apreciador das tecnologias digitais, instiga seus leitores a pensarem sobre o quanto essas tecnologias nos deixam "ocupadíssimos” - termo empregado por Powers. Mas, ainda que ocupados, nossas ações frente às telas, na maior parte do tempo, não ganham nossa total concentração e capacidade cognitiva - não são ações e tarefas feitas com profundidade e reagimos a elas por instinto, de forma automática, como é próprio do hábito, da naturalização.

Para o autor, profundidade não tem relação com o tempo despendido com determinada atividade. Para ele, profundidade "trata-se da percepção, sensação ou compreensão que vem do envolvimento com algum aspecto da vida.” (POWERS, 2012, p. 24). E quanto mais cliques, quanto mais perseguimos a correria proporcionada pelas tecnologias digitais, mais nos aproximamos da superficialidade e mais nos afastamos da concentração.

Nossa busca excessiva por tecnologias faz com que nossa existência seja pautada, segundo o autor, em uma filosofia, que é resumida na ideia de que estar conectado é bom, estar desconectado é ruim. Isso faz com que acreditemos que, quanto mais tempo passarmos conectados, melhor - uma filosofia de conectividade que envolve, segundo o autor, um duplipensar potencializado pelos veículos da mídia. Somos o que Powers chama de “maximalistas digitais”, ao maximizarmos cada vez mais nosso tempo diante das telas.

O autor diz que "a consciência digital não consegue suportar três minutos de concentração total” (2012, p. 52). Em contrapartida, para muitas pessoas, estar desconectado 
gera frustrações. No âmbito da educação, quantas críticas são feitas aos modelos pedagógicos pautados em quadro negro e giz? Quantas pessoas se frustram por sofrerem uma 'desconexão involuntária’, como esquecer o celular em casa, esquecer o carregador do notebook, ter problemas com a banda larga etc.? Estamos perdendo aos poucos qualquer intervalo entre nossas tarefas digitais - intervalo necessário para encontrar o “caminho interior”, que acarreta diretamente a perda de profundidade de nossas atividades, segundo o autor. Frente a isto, fica a pergunta: é isso o que desejamos?

Nesse jogo de dualidades, onde as telas e conexões excessivas atrapalham, mas quando utilizadas com profundidade, podem permitir um bom resultado, o desafio é encontrar um equilíbrio. E a busca por esse equilíbrio, a partir da revolução da comunicação humana, sempre fez parte da história da humanidade. Este é o fio condutor que marca a segunda parte do seu livro, intitulada “Além da multidão - os ensinamentos dos sete filósofos das telas”, que se constitui como cerne da obra. Nela, Powers traz à tona relatos divididos em sete capítulos, que envolvem sete proeminentes personalidades da cultura ocidental de diferentes épocas: Platão, Sêneca, Gutenberg, Shakespeare, Benjamim Franklin, Thoreau e McLuhan.

Powers relata que todos esses filósofos viveram em épocas diferentes e, por consequência disso, também tinham à disposição distintos recursos e ambientes tecnológicos. No entanto, suas inquietações individuais eram as mesmas: a tentativa de tirar o melhor da vida em uma sociedade cada vez mais tumultuada e apressada.

Primeiro, o autor utiliza o diálogo Fedro, de Platão (século IV a.C.), para ilustrar o quanto é necessário se afastar da multidão, para dar sentido às coisas e à vida. Se na época de Sócrates - sobre o qual Platão narra o diálogo com Fedro - a multidão referia-se à agitada Atenas, atualmente nossa multidão são as conexões, as telas. Por isso, às vezes é necessário nos afastar dos muros da cidade, ou seja, nos desconectar.

Em seguida, Powers traz Sêneca como um dos seus “filósofos das telas". Sêneca (4 a.C - 65 d.C) reconhece que para sair da multidão, é preciso ter autoconfiança - confiar nas suas próprias ideias e em seus instintos. O relato sobre Sêneca e sua busca pelo espaço interior é ilustrado pelo exemplo das cartas que o filósofo escrevia a Lucílio, seu pupilo. Afastar-se da multidão - embora envolvido por ela! - coincidia, nesse caso, com centrar a atenção em uma pessoa, ao invés de todas - utilizando-se do artifício de escrever cartas, endereçando-as a um dos seus discípulos.

Tanto no caso de Sêneca quanto no relato feito por Platão, a língua escrita teve a capacidade de libertar a mente e permitir uma experiência pessoal e reflexiva que só pode ser potencializada pela criação da prensa tipográfica por Gutenberg $(1400$ - 1468) no século XV, 
desafiando as pessoas voltarem-se para o interior, mediados pela leitura - que até então era uma atividade exterior: lia-se em voz alta, para os outros. A prensa tipográfica representou uma revolução no que se refere a experimentar a informação, o que possibilita um outro nível de profundidade. Diferentes, segundo Powers, são as tecnologias digitais atuais, que parecem justamente evitar a profundidade. Isto porque o estado de profundidade viola a regra de nunca ficar sozinho (a filosofia do "perpetuamente conectados", que permeiam as tecnologias digitais). Otimista, Powers argumenta que a humanidade é habilidosa em encontrar saídas para escapar da multidão, e cita exemplos de como o surgimento dos walkmans transformaram a experiência musical exterior em uma experiência individual e interior.

A questão da interioridade aparece também em Shakespeare (1564 - 1616), sobretudo em seu personagem Hamlet. Powers demonstra como a prensa tipográfica levou à criação de outras tecnologias de escrita individuais, pois o exercício de leitura fez com que outras pessoas sentissem vontade e necessidade de escrever. Contudo, permanecem as tecnologias antigas (a escrita e a argila) que se convertem nas "tábuas de escrita" que aparecem em Hamlet (o equivalente ao BlackBerry de hoje). Sem perder de vista a questão do equilíbrio interior e exterior (necessário ao uso das tecnologias disponíveis atualmente), Powers resgata duas personalidades mais recentes para exemplificar como é possível criar estratégias para fugir da multidão, representada pelas telas dos dispositivos digitais: Benjamin Franklin (1706 - 1790) e Henry Thoreau (1817 - 1862). No primeiro caso, trata-se de construir hábitos a partir de uma vontade interior e, no segundo, de procurar espaços de refúgios.

Se pensarmos num contexto escolar, por exemplo, a questão do não acesso excessivo à internet, por quaisquer dispositivos que seja, não pode ser pensada a partir de uma proibição do professor: ao contrário, deve partir de uma reflexão interior (nesse caso, mediada pelo professor) de por que acessar agora e não depois, por exemplo. Trata-se de uma questão de hábito, portanto. Já as zonas de refúgio são aqueles espaços em que a tecnologia não entra. A preocupação de Powers é a casa, o lar, espaços propícios à invasão das tecnologias que subvertem o convívio familiar. Mas podemos transpor essa preocupação para outros espaços para pensar o papel das perdas e dos ganhos da hiperconectividade constante em relação a outras atividades de relações sociais.

Powers finaliza esta parte do livro com as contribuições de McLuhan (1911 - 1980), mais especificamente com a sensação narcisista que envolve as pessoas com relação aos aparelhos tecnológicos: sendo os meios extensão do corpo, os homens fascinam-se por qualquer extensão de si mesmos em outros materiais que não o deles ou eles próprios. Este 
encantamento com o digital, portanto, decorre do fato de projetarmo-nos além de nós. McLuhan defende, segundo Powers, uma abordagem centrada no indivíduo, que em meio a um turbilhão de estímulos digitais encontra, com criatividade e engenhosidade, uma forma de equilibrar a vida interior e a exterior.

Na terceira parte do livro, intitulada "Em busca da pronfundidade - A teoria na prática”, Powers retoma, em dois capítulos, os aspectos tratados nos capítulos anteriores, destacando que a decisão de nos mantermos conectados o tempo todo é nossa,,ainda que muitas vezes não seja uma decisão consciente. A solução para o caos e a agitação que paira no contexto de ubiquidade e hiperconectividade urbana é adotar alguns princípios que levem a um equilíbrio da utilização das tecnologias digitais para que elas sirvam aos nossos propósitos, e não simplesmente que estejamos presos a ela, como o autor exemplifica em todos os capítulos do livro.

Para tanto, o autor propõe como sugestão - e não prescrição - um distanciamento das telas a fim de que nossa consciência volte ao mundo físico. "Sempre que abro uma distância entre mim e as telas, coisas boas acontecem. Ganho tempo e espaço para pensar na minha vida no campo digital e em todas as pessoas e informações que encontro nele. Tenho a oportunidade de interiorizar as experiências vividas na tela”. (POWERS, 2012, p. 182).

As sugestões apresentadas por Powers correspondem aos sete filósofos das telas anteriormente apresentados, que dizem respeito a sete princípios: distanciamento físico; distanciamento interior; tecnologias de introspecção; o uso de velhas ferramentas para aliviar a sobrecarga de informação; rituais positivos (hábitos); estabelecer zonas de refúgio e regular a qualidade de nossa própria experiência digital. Por fim, o autor apresenta sua experiência pessoal e de sua família sobre desconectopia, processo de distanciamento das conexões digitais adotado por ele que fez com que, aos poucos, mas de forma visceral, provocasse duas consequências: a primeira, perceber o alto custo emocional e afetivo de estar sempre conectado; a segunda, a percepção sobre a utilidade das tecnologias a fim de aproveitá-las melhor.

Há que se considerar o fato de que o autor considerou a hiperconectividade a partir de seus modos mais sobressalentes: o incômodo de uma nova mensagem de e-mail ou mensagem de texto via telefone celular (conhecida como SMS), o excesso delas, a superficialidade das notícias em tempo real e as propagandas que "pulam” na tela e desviam a atenção do indivíduo. Em todos os casos, a figura predominante é a de um consumidor de conteúdos digitais, e não a de um produtor de conteúdo, como a atividade de um blogueiro que pode realizar uma postagem virtual fruto de uma atividade de reflexão intensa, que em 
termos de processo criativo, seria muito semelhante a de um autor de um livro, sendo modificado apenas o suporte para a escrita. Em todo caso, compreende-se que a preocupação central do autor é muito mais a ação nociva da hiperconectividade, já que - podendo até soar contraditório - é um entusiasta dos benefícios tecnológicos.

Ao término da leitura, embora não seja um livro específico sobre educação, nem se trate de um livro que apresente sistematicamente uma pesquisa que lhe conferiria um caráter acadêmico, Powers ajuda-nos a pensar sobre várias questões que perpassam a cultura digital contemporânea e, consequentemente, a educação brasileira na atualidade, no que se refere às tecnologias digitais.

A constatação de Powers acerca de uma corrida global entre os países - pela disputa da posição de sociedade mais conectada do planeta - em detrimento das preocupações em destinarem recursos para fins mais humanos, como a diminuição da fome ou da falta de moradia, por exemplo, nos leva a refletir sobre as políticas públicas que estão cada vez mais voltadas para a obtenção de recursos digitais. Podemos citar o caso do Brasil, em que se expressa por meio das políticas educacionais a preocupação de incluir recursos tecnológicos nas escolas públicas, como computadores e tablets, por exemplo, mesmo que os problemas de infraestrutura básica permaneçam.

Há também a preocupação e discussões sobre como utilizar essas tecnologias de maneira pedagógica. É fato que também estamos caminhando para a obtenção de mais conectividade e mais interações por vias digitais. E os impactos vindos com a conectividade excessiva é o que faz Powers afirmar que "estamos eliminando as lacunas quando, na verdade, deveríamos estar criando mais delas.” (2012, p. 40). Então, não seria o caso de antecipar-se aos efeitos da hiperconectividade que está por vir?

No emaranhado de blogs, redes sociais, jogos on-line, e-mails e bate-papos, temos cada vez menos espaço mental para exercermos nossa criatividade e tratar, com profundidade, as questões com as quais nos defrontamos. Mas ao mesmo tempo, se pensarmos em um espaço virtual educacional e em uma escola onde todos os alunos possuem aparelhos móveis, que lhes possibilitem acessar esse ambiente de qualquer lugar, o espaço escolar deixa de ter limites. Esta conexão rompe o conceito de espaço fixo e permite a mobilidade, o que implica necessariamente na ideia de ubiquidade e na relação presença/não presença física.

Embora essas questões comecem a ser exploradas em áreas como, por exemplo, a semiologia - numa tentativa de compreender o contexto cultural digital contemporâneo - , no âmbito da educação no Brasil as discussões centrais envolvendo as tecnologias estão pautadas muito mais na questão dos seus usos para potencializar o processo educacional. Ainda 
estamos numa fase relativamente inicial das tecnologias digitais e sabemos muito pouco sobre todas as suas consequências.

No Brasil, temos as questões de acesso e inclusão tecnológica a serem resolvidas, mas talvez seja o caso de olhar para países que já superaram essa etapa e que agora buscam alternativas para enfrentar os efeitos controversos, verificados ainda muito recentemente, com o excesso de conectividade e que, no caso do nosso país, ainda não experienciamos totalmente. Neste momento, talvez a maior contribuição que O BlackBerry de Hamlet nos traz é justamente a possibilidade de perceber as implicações do excesso de conectividade que começamos a experimentar e as controvérsias que envolvem o uso das tecnologias digitais móveis no contexto de uma sociedade cada vez mais conectada e ubíqua que, em certa medida, começa a visualizar na ideia de desconectopia a possibilidade para equilibrar melhor a vida on-line e off-line. 